\title{
Perioperative management of hemophilia patients receiving total hip and knee arthroplasty: a complication report of two cases
}

This article was published in the following Dove Press journal:

Therapeutics and Clinical Risk Management

15 September 2015

Number of times this article has been viewed

\author{
Toshiyuki Tateiwa' \\ Yasuhito Takahashi',2 \\ Tsunehito Ishida' \\ Kosuke Kubo' \\ Toshinori Masaoka' \\ Takaaki Shishido' \\ Keiji Sano' \\ Kengo Yamamoto' \\ 'Department of Orthopedic Surgery, \\ ${ }^{2}$ Department of Bone and Joint \\ Biomaterial Research, Tokyo Medical \\ University, Tokyo, Japan
}

\begin{abstract}
It has been recognized that perioperative hemostasis management after joint-replacement surgery for hemophilia patients is complicated and cumbersome, due to the necessity of rigorous monitoring for clotting-factor levels throughout the infusion. Between 2005 and 2014, we examined seven patients with hemophilia A (ten joints: six hips and four knees) receiving total hip or knee arthroplasty (THA or TKA) for hemophilic arthropathy. One male patient (31 years old) showed an intra-articular hematoma formation after THA (case 1). In another male patient (46 years old) receiving TKA, the postoperative trough factor VIII level became lower significantly than reference levels ( $80 \%-100 \%$ for the $5-10$ postoperative days) recommended by the guidelines from the Japanese Society on Thrombosis and Hemostasis, despite sufficient coagulant based on the guidelines being administered (case 2). In the latter patient, deep infection and hematoma formation were observed postoperatively. In this article, we provide a detailed clinical report regarding these two complication cases at the early postoperative periods, and the management of bleeding control for hemophilia patients is discussed.
\end{abstract}

Keywords: hemophilia A, arthroplasty, clotting factor VIII levels, hematoma, infection

\section{Introduction}

Hemophilia is an X-linked congenital hemorrhagic disorder due to deficiency in clotting factors, either factor VIII (in hemophilia A) or factor IX (in hemophilia B). Some hemophilia patients can experience severe impairment in their daily activities, due to the joint destruction induced by the repeated intra-articular hemorrhaging (hemophilic arthropathy). ${ }^{1}$ Therefore, they may require receipt of total hip and knee arthroplasty (THA and TKA) potentially at a younger age than nonhemophilic patients with such joint diseases as osteoarthritis or rheumatoid arthritis. A rigorous hemostatic control as well as careful rehabilitation is essential for hemophilia patients after joint replacement by monitoring clotting-factor levels through continuous infusion. Nevertheless, even though comprehensive care was provided by a medical team of experts (doctors/nurses) in the field of hemophilia, it was previously reported that postoperative complication rates were significantly higher in hemophilic patients than nonhemophilic patients. ${ }^{2-5}$ Only a few reports have been published on the replacement of clotting factors and their activity levels in hemophilia patients after total joint arthroplasty. ${ }^{6-10}$ In these contexts, we report in detail on the postoperative transition of factor VIII-activity levels in hemophilia A patients receiving THA and TKA, and also on the observed two complications among seven hemophilia patients.
Correspondence: Toshiyuki Tateiwa Department of Orthopaedic Surgery, Tokyo Medical University, 6-7-I NishiShinjuku, Shinjuku-ku, Tokyo 160-0023, Japan

$\mathrm{Tel}+8 \mathrm{I} 3334261 \mathrm{II}$

Fax +8I 333425295

Email tateiwa@tokyo-med.ac.jp 


\section{Patients and methods}

This study was preliminarily approved by the institutional review board of Tokyo Medical University and all patients gave thier informed consent before participation in this study. We examined a total of seven hemophilic patients (ten joints: six hips and four knees) receiving THA or TKA for treatment of hemophilic arthropathy between 2005 and 2014 at our institution. THA and TKA were performed on six hips of four patients and on four knees of four patients, respectively. All patients were diagnosed with hemophilia A, of which six patients (nine joints: six hips and three knees) were categorized as a severe hemophilia with clotting factor-activity level $<1 \%$, and the remaining patient (one knee) as moderate hemophilia with an activity level of $1 \%-5 \%$. Six patients (nine joints: five hips and four knees) were hepatitis C-positive, and three patients (four joints: three hips and one knee) were HIVpositive (of which one patient exhibited low preoperative CD4 counts of 196 cells $/ \mu \mathrm{L}$ ). The mean age of the patients was 46.0 years (range: 26-61 years). The development of inhibitors to factor VIII was not detected in any case.

Cementless THA was performed by a posterolateral approach using a Mallory-Head acetabular shell (Biomet Inc, Warsaw, IN, USA) and a Bi-Metric ${ }^{\text {TM }}$ femoral stem (Biomet Inc). The acetabular liners were $33 \mathrm{kGy} \gamma$-irradiated conventional ultrahigh-molecular-weight polyethylene $\left(\mathrm{ArCom}^{\circledR}\right.$; Biomet Inc), coupled with a $28 \mathrm{~mm}$ cobalt chrome alloy. Controlled hypotensive anesthesia was performed by anesthesiologists in order to reduce perioperative blood loss. Cemented cruciate retaining-type TKA was performed by parapatellar or mid-vastus approach, and a tourniquet was used in all cases to restrain hemorrhage. Prior to implant installation, a tourniquet was deflated once in order to examine bleeding status and if necessary to achieve hemostasis. The knee-joint components were Duracon and Scorpio NRG (Stryker Corporation, Kalamazoo, MI, USA), which were implanted in three and four patients, respectively. The tibial components were $30 \mathrm{kGy} \gamma$-irradiated conventional ultrahigh-molecularweight polyethylene ( $\mathrm{N}_{2}-\mathrm{Vac}$; Stryker Corporation) coupled with cobalt chrome femoral components.

For patients prior to 2008 (four joints: two hips and two knees), perioperative hemostatic control was performed by physicians specializing in hemophilia according to the guidelines defined by the World Federation of Hemophilia. ${ }^{1}$ On the other hand, for patients after 2008 (six joints: four hips and two knees), the arthroplasty procedures were performed in accordance with the guidelines defined by the Japanese Society on Thrombosis and Hemostasis. ${ }^{11}$ The latter guidelines recommend that trough clotting-factor levels should be maintained between $80 \%$ and $100 \%$ by conducting continuous infusion for 5-10 postoperative days (PODs), and subsequently be controlled between $20 \%$ and $80 \%$ depending on the postoperative course of patients.

The median (25th-75th percentile) operation time, intraoperative bleeding amount, and postoperative bleeding amount were 92.0 (72.5-107.0) minutes (THA 80.5 [58.8-89.3] minutes, TKA 107.0 [101.0-108.5] minutes), $322.0(204.5-605.0) \mathrm{mL}$ (THA 427.5 [242.0-885.5] mL, TKA 263.5 [165.5-342.8] mL), and 592.0 (390.8-991.0) mL (THA 497.5 [253.5-1,282.5] mL, TKA 671.0 [500.8-857.0] mL), respectively. Drain-tube removal, getting out of bed, and ambulation were done on a median of POD 3.0 (2.0-3.0) (THA 2.5 [2.0-3.0], TKA 3.0 [3.0-4.5]), 3.0 (2.8-4.3) (THA 3.0 [2.0-4.3], TKA 3.5 [3.0-4.8]), and 6.0 (4.0-8.3) (THA 5.5 [4.0-9.3], TKA 7.0 [4.5-8.8]), respectively.

Perioperatively administered clotting factor VIII was Advate $^{\circledR}$ (Baxter International Inc, Deerfield, IL, USA) for six joints (four hips, two knees), Kogenate ${ }^{\circledR}$ FS (Bayer AG, Leverkusen, Germany) for one joint (one hip), Recombinate ${ }^{\circledR}$ (Baxter) for two joints (one hip, one knee), and CrossEight $\mathrm{M}^{\circledR}$ (Japanese Red Cross Society, Tokyo, Japan) for one joint (one knee). A single intravenous injection of factor VIII by bolus administration was conducted preoperatively for one patient (one knee) with moderate hemophilia. For six patients (six hips, three knees) with severe hemophilia, preoperative single intravenous injection by continuous infusion was conducted initially and then switched to bolus administration.

We confirmed that one male patient receiving THA showed an intra-articular hematoma (henceforth referred to as case 1). In another male patient receiving TKA, we observed that the trough factor VIII level was significantly lower than the reference value defined in the aforementioned Japanese guidelines. ${ }^{11}$ The latter patient experienced deep infection and hematoma formation postoperatively (henceforth referred to as case 2). In the next section, we provide a detailed clinical report regarding these two patients with early postoperative complications.

\section{Results}

\section{Case I}

The patient was a 31-year-old male (height $180 \mathrm{~cm}$, weight $95 \mathrm{~kg}$, body mass index [BMI] $29.3 \mathrm{~kg} / \mathrm{m}^{2}$ ) with severe hemophilia A. He was HIV-positive, and had undergone insulin therapy for diabetes mellitus. Preoperative CD4 count, blood glucose level, and $\mathrm{HbA}_{1 \mathrm{c}}$ level were 196 cells $/ \mu \mathrm{L}, 198 \mathrm{mg} / \mathrm{dL}$, and $7.1 \%$, respectively. The severity of the affected hip joint was stage $\mathrm{V}$ according to the Arnold-Hilgartner classification 

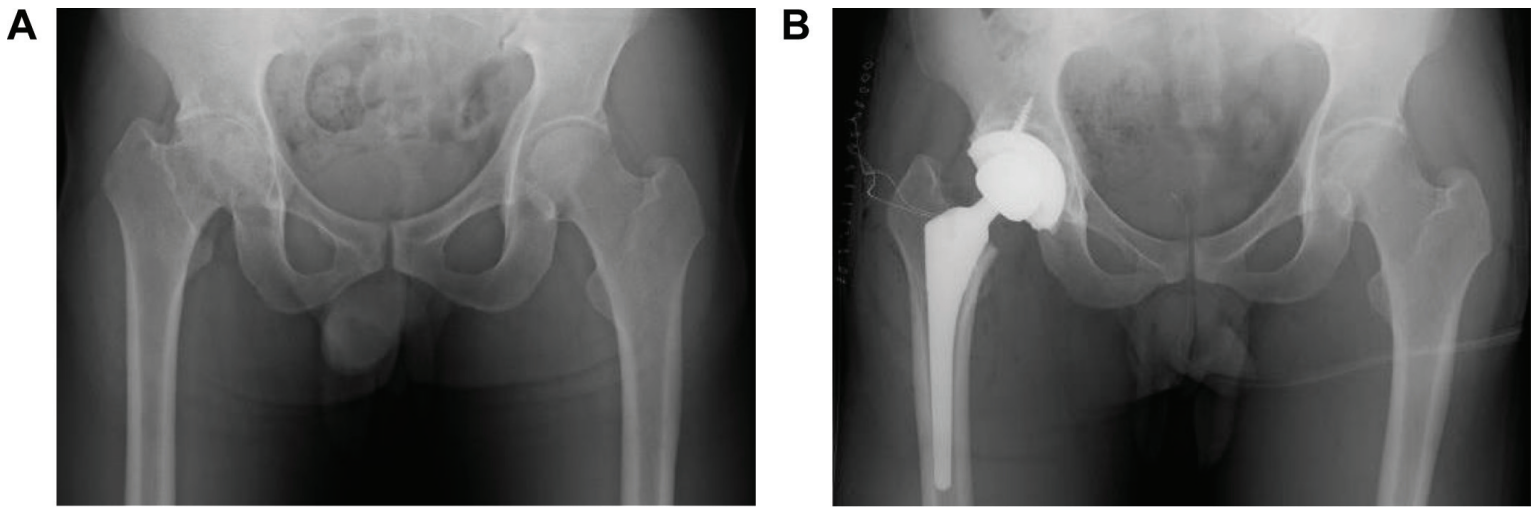

Figure I Anteroposterior hip radiographs of case I (3I-year-old male with severe hemophilia). Note: (A) Before and (B) after total hip arthroplasty.

(Figure 1A). ${ }^{12}$ Cementless THA was performed using the posterolateral approach. The postoperative radiograph was shown in Figure 1B. The operation time was 102 minutes. The amount of intraoperative and postoperative bleeding was $908 \mathrm{~mL}$ and $570 \mathrm{~mL}$, respectively. On POD 2, the patient started using a wheelchair after the removal of the drainage tube. Ambulation exercises started from POD 6 , and the patient was discharged on POD 16. Clotting factor VIII (Kogenate FS) was administered preoperatively (3,000 IU/day just prior to THA), and subsequently continuous infusion was conducted at $4 \mathrm{IU} / \mathrm{kg} / \mathrm{h}$ (Figure $2 \mathrm{~A}$ and $\mathrm{B}$ ). The trough factor VIII level was $185 \%$ immediately after THA. From POD 1, the dosage was reduced to $3.1 \mathrm{IU} / \mathrm{kg} / \mathrm{h}$, and then the factor level decreased to $114 \%$ and $121 \%$ on PODs 1 and 3, respectively (Figure 2B and C). After being discharged from the hospital, the patient was rehospitalized due to hematoma formation. On POD 71, surgical removal of the hematoma was performed (Figure 3).

\section{Case 2}

The patient was a 46-year-old male (height $152 \mathrm{~cm}$, weight $50 \mathrm{~kg}$, BMI $21.6 \mathrm{~kg} / \mathrm{m}^{2}$ ) with severe hemophilia A and hepatitis $\mathrm{C} / \mathrm{HIV}$-positive. The preoperative CD4 count was 892 cells $/ \mu L$. The severity of the affected knee joint was stage IV according to the Arnold-Hilgartner classification (Figure 4A and B). ${ }^{12}$ Cemented cruciate retaining-type TKA was performed by the mid-vastus approach. The operation time was 99 minutes, and the amount of intraoperative bleeding was $224 \mathrm{~mL}$. Postoperative radiographs are shown in Figure $4 \mathrm{C}$ and D. Although a drainage tube was kept inserted after TKA, frequent dressing replacement was needed, due to a large amount of subcutaneous bleeding. The amount of postoperative bleeding was $614 \mathrm{~mL}$. The patient started using a wheelchair after the removal of drainage tube on POD 3.
Ambulation and range-of-motion exercises started from POD 4. However, the exercises were discontinued, due to the low trough factor VIII level (70\%) on POD 6. Pain and swelling of the left knee joint increased from POD 10. A severe fever $\left(39^{\circ} \mathrm{C}\right)$ was observed on POD 12 , and coagulase-negative Staphylococcus was detected from blood culture and aspirate samples. The patient was thus diagnosed with early deep infection following TKA. Surgical debridement was performed, and closed continuous irrigation was initiated. According to our observation during the debridement, a hematoma filled in the intra-articular cavity and connected to the distal subcutaneous area (Figure 5), which implies a possible route of infection.

Clotting factor VIII (Advate) was administered preoperatively (3,000 IU/day just prior to TKA), and subsequently continuous infusion was conducted at $4 \mathrm{IU} / \mathrm{kg} / \mathrm{h}$ (Figure $6 \mathrm{~A}$ and B). The trough factor VIII level was $90 \%$ on POD 1, and the dosage of Advate was then increased to $4.8 \mathrm{IU} / \mathrm{kg} / \mathrm{h}$ (Figure 6A and B). The trough level increased to $113 \%$ on POD 2, but subsequently decreased to $72 \%$ and $36 \%$ on PODs 6 and 9, respectively. Although sufficient clotting factor was administered according to the Japanese guidelines, ${ }^{11}$ trough factor VIII activity remained at much lower levels than the reference (ie, $80 \%-100 \%$ ). Note that there was no development of factor VIII inhibitors in this case.

\section{Discussion}

Postoperative complications, including hematoma and infection, have previously been reported for hemophilia patients, ${ }^{2,3,13,14}$ and thus it has been considered that rigorous hemostatic control should be performed for hemophilia patients through clotting-factor replacement after arthroplasty. According to recent publications on hemophilia patients receiving TKA, postoperative complication rates 

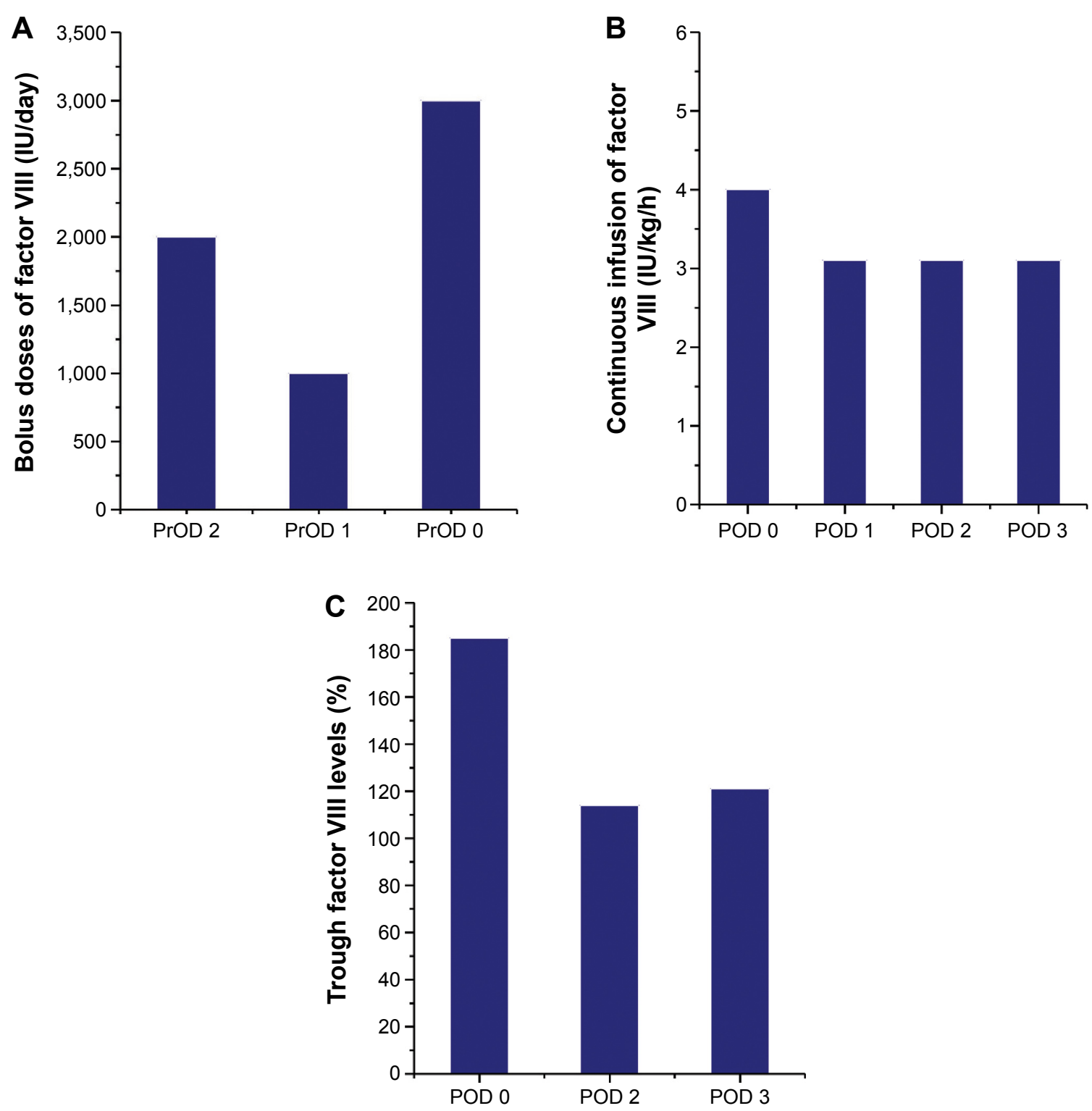

Figure 2 Perioperative management of clotting factor VIII (Kogenate FS) for case I.

Notes: (A) Bolus doses of factor VIII on preoperative days (PrODs); (B) continuous infusion of factor VIII on postoperative days (PODs); (C) postoperative trough factor VIII levels.
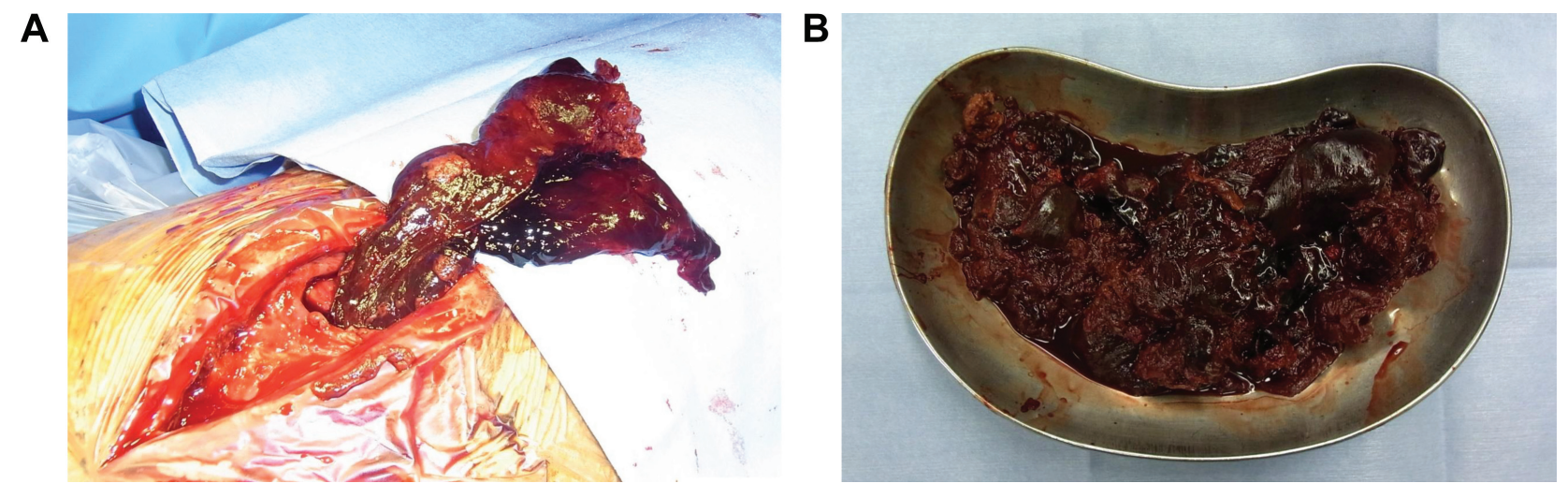

Figure 3 Photographs of hematoma in case I (3I-year male with severe hemophilia A). Notes: (A) Intraoperative view of $300 \mathrm{~g}$ hematoma filled in the intra-articular cavity; (B) the hematoma after surgical removal. 

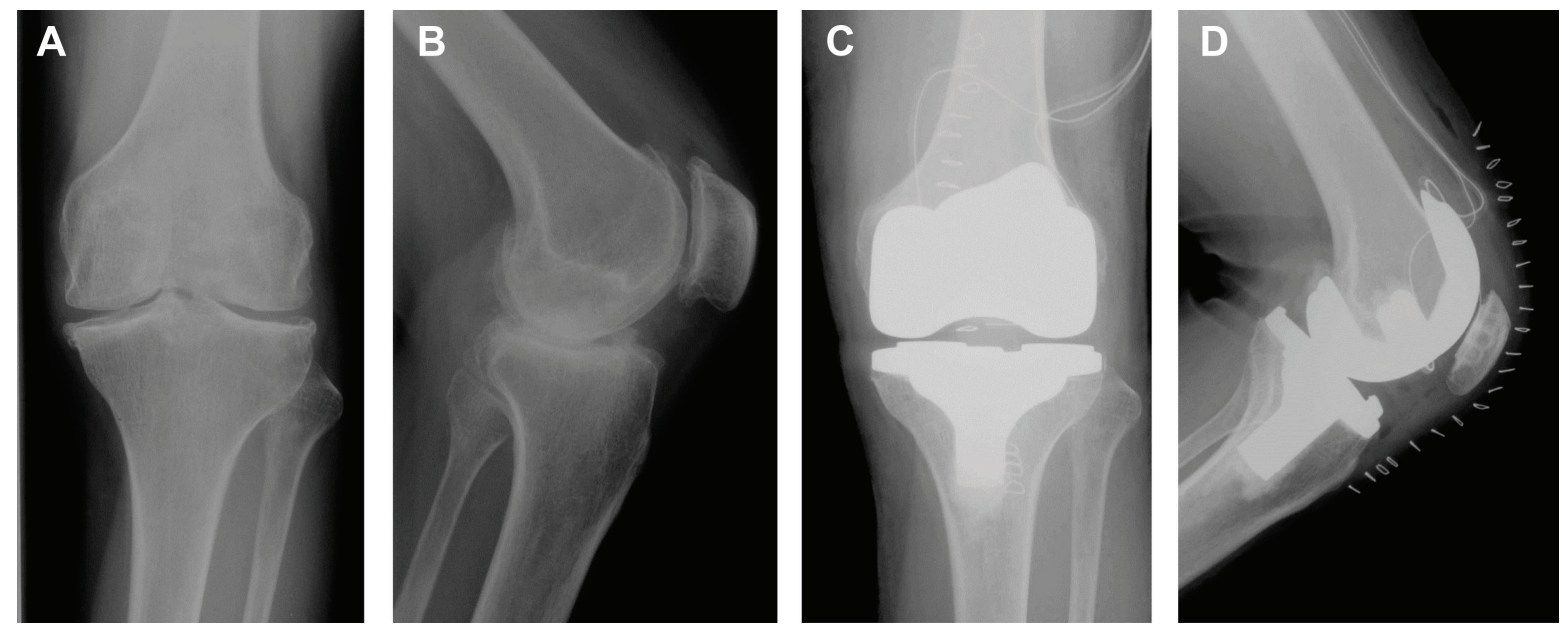

Figure 4 Anteroposterior and lateral knee radiographs of case 2 (46-year-old male). Note: (A, B) Before and (C, D) after total knee arthroplasty.

were $2.8 \%-12.5 \%$ for hematoma and $1.4 \%-15.5 \%$ for infection, and revision rates were $4.6 \%-20.0 \%$ at a mean follow-up of 5.1-11.8 years. $^{2-5,15}$ Although hemophilia patients receiving THA showed a lower risk of hematoma and infection, higher revision rates $(7.4 \%-13.3 \%)$ were reported at a mean follow-up of 6.3-11.0 years compared to hemophilia patients receiving TKA. Therefore, both THA and TKA are likely to entail greater risks of failure for hemophilic patients than nonhemophilic patients. Furthermore, it is considered that HIV-positive patients with CD4

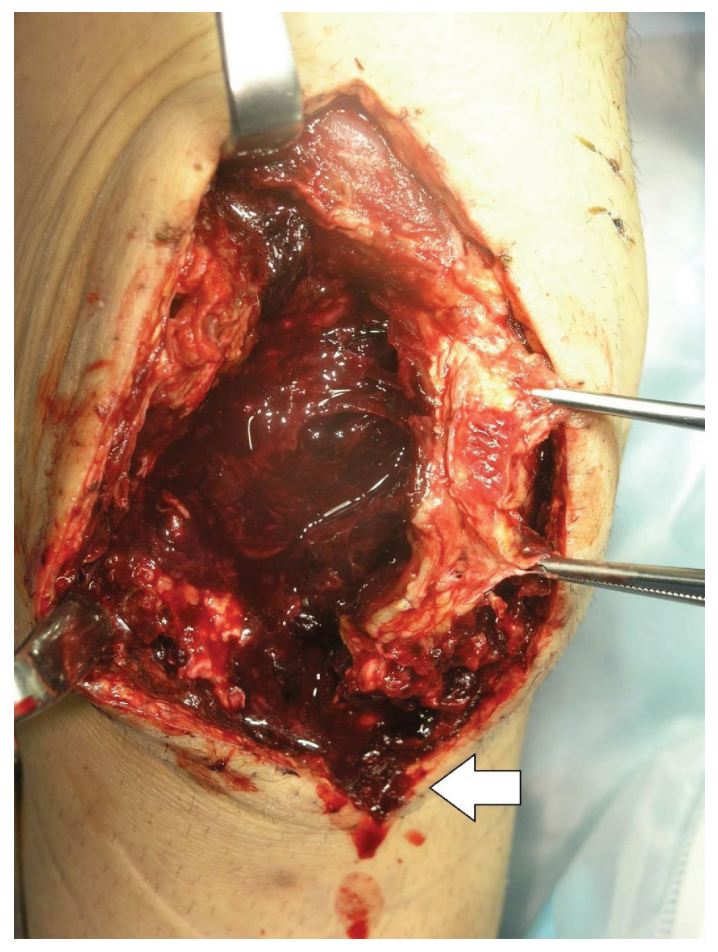

Figure 5 Intraoperative view of hematoma connecting to the distal subcutaneous area (white arrow) in case 2 (46-year-old male). counts of $\leq 200$ cells/ $\mu \mathrm{L}$ can also be exposed to a higher risk of infection, ${ }^{16}$ and repeated self-administration of clotting factors may become a route of infection. ${ }^{17-19}$ In general, hemophilia patients are often HIV-positive, and there has been a lot of research done regarding a correlation between postoperative infection and HIV. ${ }^{4,15,219-22}$ Nevertheless, this correlation remains to be fully elucidated for hemophilia patients.

In the current report, one male patient infected at an early POD (case 2) required frequent dressing replacement due to continuous bleeding from the surgical wound. According to the intraoperative findings after the infection, a hematoma filled in the intra-articular cavity and connected to the distal subcutaneous area, which was considered a possible route of the infection. Poor postoperative hemostatic control can delay the initiation of range-of-motion or ambulation exercise, due to the necessity of bed rest. In addition, the formation of an intra-articular hematoma can lead to prosthetic loosening and consequently to an increased rate of revision arthroplasty. Therefore, in the perioperative and postoperative periods, clotting-factor replacement is regarded as one of the most important treatment strategies for preventing complications. This treatment commonly starts during the operation, since clotting-factor levels are more easily controlled by continuous infusion than bolus administration.

Negrier et $\mathrm{a}^{23}$ recommended using Advate at an initial dose of 3.2-3.7 IU/ $/ \mathrm{kg} / \mathrm{h}$, while Takedani ${ }^{9}$ reported initial mean doses of Kogenate FS, Advate, and CrossEight $\mathrm{M}$ for continuous infusion during arthroplasty of $2.9 \pm 0.3,3.5 \pm 0.9$, and $3.2 \pm 0.5 \mathrm{IU} / \mathrm{kg} / \mathrm{h}$, respectively. In our present case of early postoperative infection (case 2), the initial mean dose for continuous infusion of Advate 
A

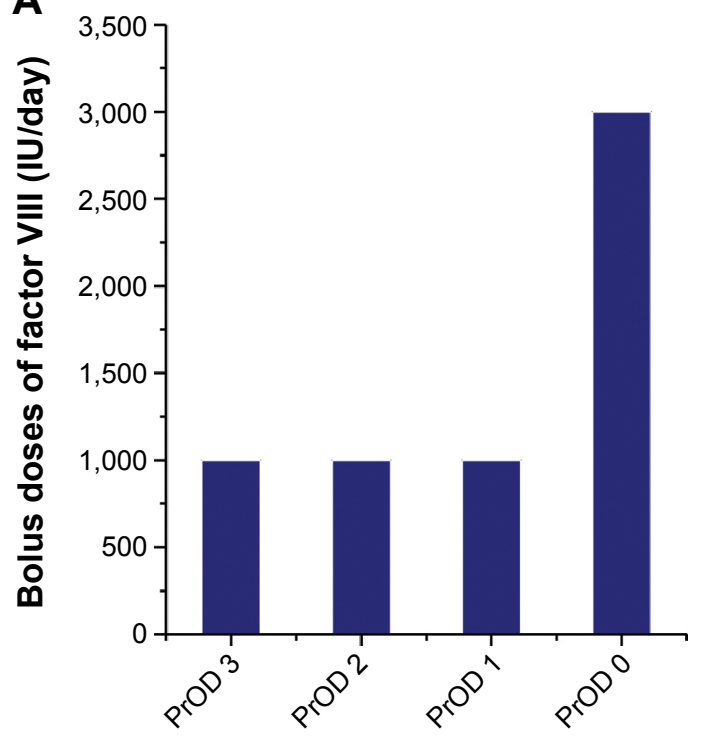

B

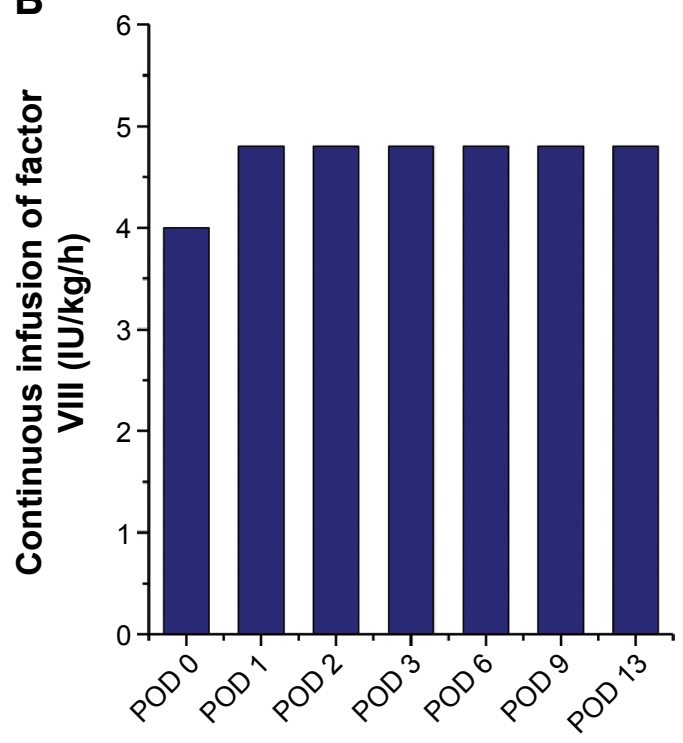

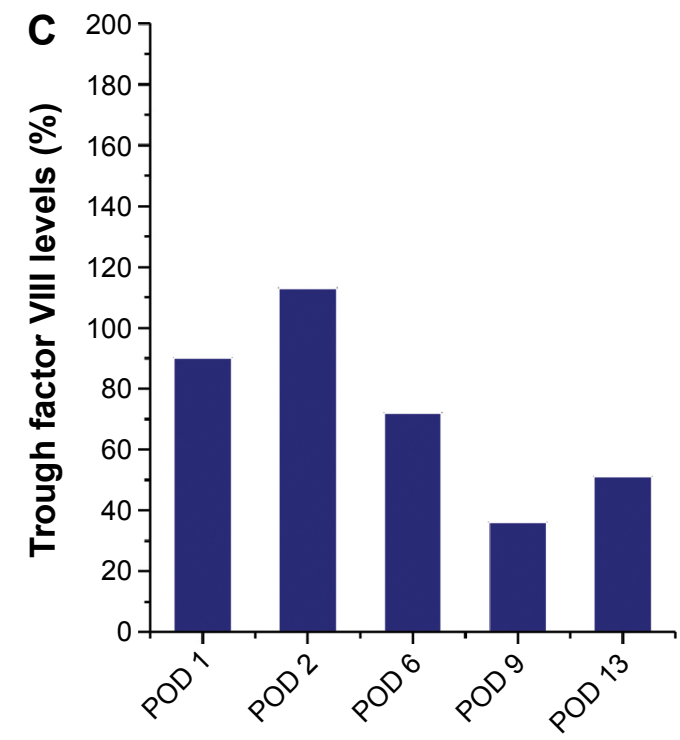

Figure 6 Perioperative management of clotting factor VIII (Advate) for case 2.

Notes: (A) Bolus doses of factor VIII on preoperative days (PrODs); (B) continuous infusion of factor VIII on postoperative days (PODs); (C) postoperative trough factor VIII levels.

was $4.0 \mathrm{IU} / \mathrm{kg} / \mathrm{h}$ and then increased to $4.8 \mathrm{IU} / \mathrm{kg} / \mathrm{h}$. Nevertheless, we found clotting-factor levels decreased (Figure 6B and C).

Since only a small fraction of factor VIII circulates outside the vascular system, several authors have reported that underweight patients are subject to being underdosed and obese patients to being overdosed by applying the following formula: dose $=($ body weight $[\mathrm{kg}] \times$ desired factor VIII increase [\%] $/ 2 .{ }^{24-27}$ Henrard et $\mathrm{al}^{26}$ proposed that factor VIII dosing can be adjusted for patients with a BMI $<20 \mathrm{~kg} / \mathrm{m}^{2}$ or $\geq 30 \mathrm{~kg} / \mathrm{m}^{2}$. In this study, the BMI of cases 1 and 2 was 29.3 and $21.6 \mathrm{~kg} / \mathrm{m}^{2}$, respectively, and thus the currently applied doses based on the guidelines ${ }^{1,11}$ seem to be acceptable for those patients.
According to a report by Wong et $\mathrm{al}^{13}$ on $556 \mathrm{knees}$ following TKA, the postoperative infection rate was $9.2 \%$ in the patient group receiving clotting-factor replacement based on the World Federation of Hemophilia guidelines. ${ }^{1}$ On the other hand, the other patient group, maintaining higher clotting-factor levels than the guidelines' recommendation, exhibited a significantly lower infection rate $(2.5 \%)$. Note that we experienced some patients with significantly reduced activity levels regardless of the proper administration based on the guidelines. This fact can suggest great importance in maintaining a higher level of each factor than the guidelines' recommendation through careful daily monitoring.

The hematoma formation observed in case 1 can be associated with the discontinued self-administration of the 
clotting factor after his discharge from the hospital. Therefore, adequate instruction for continuous self-administration should be given to a hemophilia patient who undergoes joint-replacement surgery. Moreover, it should be carefully considered whether or not a compromised host with HIV or diabetes is a proper candidate for arthroplasty. Lastly, in order to control bleeding, it is essential to conduct daily monitoring of clotting factor-activity levels through close cooperation among orthopedists, hemophilia experts, and physiotherapists.

\section{Disclosure}

The authors report no conflicts of interest in this work.

\section{References}

1. World Federation of Hemophilia. Guidelines for the Management of Hemophilia. Montreal: WFH; 2005.

2. Rodriguez-Merchan EC, Gomez-Cardero P, Jimenez-Yuste V. Infection after total knee arthroplasty in haemophilic arthropathy with special emphasis on late infection. Haemophilia. 2011;17(5):e831-e832.

3. Wang K, Street A, Dowrick A, Liew S. Clinical outcomes and patient satisfaction following total joint replacement in haemophilia - 23-year experience in knees, hips and elbows. Haemophilia. 2012;18(1): 86-93.

4. Solimeno LP, Mancuso ME, Pasta G, Santagostino E, Perfetto S, Mannucci PM. Factors influencing the long-term outcome of primary total knee replacement in haemophiliacs: a review of 116 procedures at a single institution. Br J Haematol. 2009;145(2):227-234.

5. Silva M, Luck JV. Long-term results of primary total knee replacement in patients with hemophilia. J Bone Joint Surg Am. 2005;87(1): 85-91.

6. Zingg PO, Fucentese SF, Lutz W, Brand B, Mamisch N, Koch PP. Haemophilic knee arthropathy: long-term outcome after total knee replacement. Knee Surg Sports Traumatol Arthrosc. 2012;20(12): 2465-2470.

7. Yoo MC, Cho YJ, Kim KI, Ramteke A, Chun YS. The outcome of cementless total hip arthroplasty in haemophilic hip arthropathy. Haemophilia. 2009;15(3):766-773.

8. Bae DK, Yoon KH, Kim HS, Song SJ. Total knee arthroplasty in hemophilic arthropathy of the knee. J Arthroplasty. 2005;20(5):664-668.

9. Takedani H. Continuous infusion during total joint arthroplasty in Japanese haemophilia A patients: comparison study among two recombinants and one plasma-derived factor VIII. Haemophilia. 2010; 16(5):740-746.

10. Sheth DS, Oldfield D, Ambrose C, Clyburn T. Total knee arthroplasty in hemophilic arthropathy. J Arthroplasty. 2004;19(1):56-60.

11. Japanese Society on Thrombosis and Hemostasis. [Acute hemorrhage in hemophilia patients without inhibitors: guidelines for clotting factor replacement therapy in the treatment and surgery]. 2008. Available from: http://www.jsth.org/committee/pdf/03_inhibitor_H1_B.pdf. Accessed August 24, 2015. Japanese.

Therapeutics and Clinical Risk Management

\section{Publish your work in this journal}

Therapeutics and Clinical Risk Management is an international, peerreviewed journal of clinical therapeutics and risk management, focusing on concise rapid reporting of clinical studies in all therapeutic areas, outcomes, safety, and programs for the effective, safe, and sustained use of medicines. This journal is indexed on PubMed Central, CAS,
12. Arnold WD, Hilgartner MW. Hemophilic arthropathy. Current concepts of pathogenesis and management. J Bone Joint Surg Am. 1977; 59(3):287-305.

13. Wong JM, Mann HA, Goddard NJ. Perioperative clotting factor replacement and infection in total knee arthroplasty. Haemophilia. 2011; 18(4):1-6.

14. Sikkema T, Boerboom AL, Meijer K. A comparison between the complications and long-term outcome of hip and knee replacement therapy in patients with and without haemophilia; a controlled retrospective cohort study. Haemophilia. 2011;17(2):300-303.

15. Goddard NJ, Mann HA, Lee CA. Total knee replacement in patients with end-stage haemophilic arthropathy: 25-year results. $J$ Bone Joint Surg Br. 2010;92(8):1085-1089.

16. Ragni MV, Crossett LS, Herndon JH. Postoperative infection following orthopaedic surgery in human immunodeficiency virus-infected hemophiliacs with CD4 counts $<$ or $=200 / \mathrm{mm}^{3} . J$ Arthroplasty. 1995 ; 10(6):716-721.

17. Chiang CC, Chen PQ, Shen MC, Tsai W. Total knee arthroplasty for severe haemophilic arthropathy: long-term experience in Taiwan. Haemophilia. 2008;14(4):828-834.

18. Luck JV, Silva M, Rodriguez-Merchan EC, Ghalambor N, Zahiri CA, Finn RS. Hemophilic arthropathy. J Am Acad Orthop Surg. 2004;12(4): 234-245.

19. Norian JM, Ries MD, Karp S, Hambleton J. Total knee arthroplasty in hemophilic arthropathy. J Bone Joint Surg Am. 2002;84(7): $1138-1141$.

20. Rodriguez-Merchan EC. Total knee replacement in haemophilic arthropathy. J Bone Joint Surg Br. 2010;89(2):186-188.

21. Goddard NJ, Rodriguez-Merchan EC, Wiedel JD. Total knee replacement in haemophilia. Haemophilia. 2002;8(3):382-386.

22. Hicks JL, Ribbans WJ, Buzzard B, et al. Infected joint replacements in HIV-positive patients with haemophilia. J Bone Joint Surg Br. 2001; 83(7):1050-1054.

23. Negrier C, Shapiro A, Berntorp E, et al. Surgical evaluation of a recombinant factor VIII prepared using a plasma/albumin-free method: efficacy and safety of Advate in previously treated patients. Thromb Haemostasis. 2008;100(2):217-223.

24. Björkman S, Berntorp E. Pharmacokinetics of coagulation factors: clinical relevance for patients with haemophilia. Clin Pharmacokinet. 2001;40(11):815-832.

25. Björkman S, Blanchette VS, Fischer K, et al. Comparative pharmacokinetics of plasma- and albumin-free recombinant factor VIII in children and adults: the influence of blood sampling schedule on observed age-related differences and implications for dose tailoring. J Thromb Haemost. 2010;8(4):730-736.

26. Henrard S, Speybroeck N, Hermans C. Impact of being underweight or overweight on factor VIII dosing in hemophilia A patients. Haematologica. 2013;98(9):1481-1486.

27. Graham A, Jaworski K. Pharmacokinetic analysis of anti-hemophilic factor in the obese patient. Haemophilia. 2014;20(2):226-229. 